\section{Correspondence}

\section{Check for updates}

\section{OPEN ACCESS}

\section{Received: Dec 15, 2018}

Accepted: Feb 21, 2019

\section{Address for Correspondence: \\ Hyun Soo Park, MD, PhD, MPH \\ Department of Obstetrics and Gynecology, \\ Dongguk University Ilsan Hospital, 27 \\ Dongguk-ro, Ilsandong-gu, Goyang 10380, \\ Republic of Korea. \\ E-mail:hsparkmd@gmail.com}

(c) 2019 The Korean Academy of Medical

Sciences.

This is an Open Access article distributed under the terms of the Creative Commons Attribution Non-Commercial License (https:// creativecommons.org/licenses/by-nc/4.0/) which permits unrestricted non-commercial use, distribution, and reproduction in any medium, provided the original work is properly cited.

ORCID iDs

Hyun Soo Park (1D)

https://orcid.org/0000-0002-7873-3234

Disclosure

The author has no potential conflicts of interest to disclose.

\title{
Cerebral Palsy Rate of Very Low Birth Weight Infants Born at 36 Weeks of Gestation
}

\author{
Hyun Soo Park (i) \\ Department of Obstetrics and Gynecology, Dongguk University Ilsan Hospital, Goyang, Korea \\ - See the article "National Registry Data from Korean Neonatal Network: Two-Year Outcomes of \\ Korean Very Low Birth Weight Infants Born in 2013-2014" in volume 33, number 48, e309.
}

Youn et al. ${ }^{1}$ reported two-year outcomes of Korean very low birth weight infants (VLBWIs). Compared to the lower overall incidence of cerebral palsy (CP) in Korea, which decreased from $0.41 \%$ in 2007 to $0.25 \%$ in $2011,{ }^{2} \mathrm{CP}$ rate in VLBWIs was higher and over $6 \%$. The rate is even more striking when VLBWIs born at 36 weeks of gestation were considered, which amounts to $20 \%$.

As 3rd percentile birth weight of Korean babies born at 36 weeks of gestation is over 2,000 grams, ${ }^{3}$ VLBWIs born at 36 weeks of gestation are placed at the lowest extreme in birth weight and should have been delivered earlier. Therefore, the high percentage of $\mathrm{CP}$ in this gestational age group indicates inadequate prenatal care which should be corrected. In addition, it is not difficult to assume that the number of VLBWIs born at 36 weeks of gestation should be very small. According to the data from Microdata Integrated Service provided by the Statistics Korea, the number of VLBWIs born at 36 weeks of gestation in 2013 and 2014 were 25 (excluding cases reported as 0 gram in the data) and 34, respectively. ${ }^{4}$ Based on the number of VLBWIs $(n=25)$ and the rate (proportion $=0.2)$, we can calculate the exact binomial 95\% confidence interval (CI) of the CP rate of VLBWIs born at 36 weeks in 2013 as 0.068-0.407 using the STATA ver 14.0 (STATACorp LLC, College Station, TX, USA). As the statistics were extracted from records of all deliveries in the country, the number in this report would be smaller. Accordingly, although the point estimate of the rate of $\mathrm{CP}$ in babies born at 36 weeks of gestation is very high, the CI will be wider. I believe that the $20 \%$ of CP rate of VLBWIs born at 36 weeks of gestation should be interpreted in this context. It would be preferable for the authors to present the numbers of CPs and CIs along with point estimate (percent). It should also be mentioned that it is unclear whether the CP rate of VLBWIs born at 36 weeks of gestation in 2014 is indeed $20 \%$ which is not evident in Fig. 2, even if 37 is a misprint of 36 in the horizontal axis.

\section{REFERENCES}

1. Youn Y, Lee SM, Hwang JH, Cho SJ, Kim EK, Kim EA, et al. National registry data from Korean Neonatal Network: two-year outcomes of Korean very low birth weight infants born in 2013-2014.J Korean Med Sci 2018;33(48):e309.

PUBMED | CROSSREF 
2. Kim SW, Jeon HR, Shin JC, Youk T, Kim J. Incidence of cerebral palsy in Korea and the effect of socioeconomic status: a population-based nationwide study. Yonsei Med J 2018;59(6):781-6. PUBMED | CROSSREF

3. Lim JS, Lim SW, Ahn JH, Song BS, Shim KS, Hwang IT. New Korean reference for birth weight by gestational age and sex: data from the Korean Statistical Information Service (2008-2012). Ann Pediatr Endocrinol Metab 2014;19(3):146-53. PUBMED | CROSSREF

4. Statistics Korea. Microdata integrated service. https://mdis.kostat.go.kr/index.do. Updated 2018. Accessed Dec 15, 2018. 